\title{
Biology, systematics, and clinical manifestations of Zygomycota infections
}

\author{
A. Muszewska • J. Pawlowska • P. Krzyściak
}

Received: 12 December 2013 / Accepted: 31 January 2014 /Published online: 11 March 2014

(C) The Author(s) 2014. This article is published with open access at Springerlink.com

\begin{abstract}
Fungi cause opportunistic, nosocomial, and community-acquired infections. Among fungal infections (mycoses) zygomycoses are exceptionally severe, with a mortality rate exceeding $50 \%$. Immunocompromised hosts, transplant recipients, and diabetic patients with uncontrolled ketoacidosis and high iron serum levels are at risk. Zygomycota are capable of infecting hosts immune to other filamentous fungi. The infection often follows a progressive pattern, with angioinvasion and metastases. Moreover, current antifungal therapy frequently has an unfavorable outcome. Zygomycota are resistant to some of the routinely used antifungals, among them azoles (except posaconazole) and echinocandins. The typical treatment consists of surgical debridement of the infected tissues accompanied by amphotericin B administration. The latter has strong nephrotoxic side effects, which make it unsuitable for prophylaxis. Delayed administration of amphotericin and excision of mycelium-containing tissues worsens survival prognoses. More than 30 species of Zygomycota are involved in human infections, among them Mucorales is the most abundant. Prognosis and treatment suggestions differ for each species, which makes fast and
\end{abstract}

Electronic supplementary material The online version of this article (doi:10.1007/s10096-014-2076-0) contains supplementary material, which is available to authorized users.

\footnotetext{
A. Muszewska $(\bowtie)$

Institute of Biochemistry and Biophysics, Polish Academy of

Sciences, Pawiskiego 5a, 02-106 Warsaw, Poland

e-mail: musze@ibb.waw.pl

J. Pawlowska

Department of Plant Systematics and Geography, University of Warsaw, Al. Ujazdowskie 4, 00-478 Warsaw, Poland

P. Krzyściak

Department of Mycology, Chair of Microbiology, Jagiellonian University Medical College, 18 Czysta Street, 31-121 Krakow, Poland
}

reliable diagnosis essential. Serum sample PCR-based identification often gives false-negative results; culture-based identification is time-consuming and not always feasible. With the dawn of Zygomycota sequencing projects significant advancement is expected, as in the case of treatment of Ascomycota infections.

\section{Introduction}

Zygomycota is an artificial grouping of distantly related basal fungi. This term is broadly used for fungi belonging to Mucoromycotina, Entomophthoromycotina, Mortierellomycotina, Zoopagomycotina, and Kickxellomycotina. The common name zygomycosis indicates infections caused by organisms that diverged more than 800 MYA [1], preceding land colonization by plants. Consequently, it should be broadly recognized that zygomycoses have a variable prognosis depending on the causal agent and patient's condition. Mycology is undergoing a significant shift toward molecular-based taxonomy, aiming at a more consistent classification and nomenclature. A robust classification reflecting biological similarities is of great significance for medical purposes. The biochemical and physiological variability among fungal taxa lead to measurable effects, among them antifungal resistance [2, 3]. Fast and accurate species (or at least genus) recognition is essential for a successful treatment in the case of less common fungi. Yet, in most laboratories such in-depth classification is not routinely performed, because these genera cannot be easily differentiated, for example, histopathologically.

The broadly used and recognized term Zygomycota should be abandoned in the future, in favor of proper taxonomic names. Since the clinical manifestations and development of infections with Mucorales and Entomophthorales are significantly different, the name "zygomycosis" should also be 
abandoned in favor of entomophthoromycosis (entomophthoromycosis), mortierellomycosis and mucoralomycosis (mucormycosis). However, here, when describing the common features of many taxa, we will apply the term Zygomycota. Emerging Zygomycota infections are becoming a serious threat at transplantation and on other wards with immunocompromised patients. This phenomenon become more pronounced after the introduction of serumbased detection, diagnostic imaging, and modern antifungals (voriconazole) that enabled efficient treatment of aspergillosis [4]. Mucorales are the third most common agent of systemic mycoses after invasive aspergillosis and candidiasis in hematology patients [5]. This constantly growing group of susceptible patients, together with improvements in the management of invasive aspergillosis and candidiasis result in increased interest in zygomycoses. In contrast to aspergillosis, most cases of zygomycosis are fatal, despite the administration of antifungal therapy [6-8]. The number of at-risk patients is constantly growing, with the ubiquity of diabetes and immunosuppressive treatment. Furthermore, Zygomycota are able to colonize hosts not susceptible to other opportunistic fungal infections, among them diabetic patients and intravenous drug users [8]. In particular, representatives of the genus Basidiobolus [9] and of the family Saksenaeaceae [10, 11] have been reported to infect healthy hosts.

Here, we revise current knowledge on nomenclature, pathogenesis, and diagnostics of zygomycosis (mainly mucormycosis).

\section{Biology}

Mucoromycotina representatives are ubiquitous organisms present all over the world in the soil, infecting plants and other fungi [12]. Importantly, the same species are found in clinical samples and used in food fermentation. Entomophthoromycotina groups more than 250 entomopathogenic, soil, and litter-associated species [13]. Mortierellomycotina [14] harbor more than 100 taxa of saprotrophic soil organisms.

The knowledge on pathogenic Zygomycota ecology is very limited and often anecdotal. Understanding the lifestyle of pathogenic species is essential to understanding the epidemiology and to formulating recommendations for at-risk patients. In medical mycology species from the order Mucorales are the most common Zygomycota representatives.

Mucorales reproduce both sexually, by zygospores formed after the fusion of hyphae of different mating types, and asexually through sporangiospores produced within sporangia. However, in most species zygospores production is rarer and the conditions necessary for their formation and germination remain unknown. In turn, asexual spores are produced in massive quantities and they can differ in character [15]. Mucorales produce not only dry sporangiospores dispersed by the air, but also wet sporangiospores, less prone to aerosolization. Spore size and hydrophilic/hydrophobic character impacts the dispersal of fungi. Zygomycetes that infect humans are relatively hydrophilic, which limits everyday exposure to their spores, even if they are ubiquitous in spoiled food and their pathogenic strains do not differ from environmental samples [16].

Even the most ubiquitous among Zygomycota (Rhizopus and Mucor) are less common in air samples than the benign, plant-associated Alternaria and Cladosporium [17, 18] involved in human allergies. The prevalence of Mucorales spores in dust and spoiled food compared with air samples is consistent with the onset of infections after earthquakes and massive inhalation of spores. Human pathogenic Ascomycota are broadly encountered in air samples, whereas Zygomycota are less abundant in air samples [19-21]. In liquid culture Mucor circinelloides produces yeast cells; however, the role of yeast forms in infection is unknown [22]. Furthermore, M. circinelloides produces sporangiospores of different sizes depending on the mating type variant [23]. The bigger sporangiospores are able to lyse macrophages, which makes them more virulent to a mammalian host.

Until recently, it was not clear whether the dimorphic switch between aerobic hyphal growth and multi-budded yeast growth under anaerobic/high $\mathrm{CO}_{2}$ conditions is related to virulence in Mucorales. Lee and colleagues [24] showed that a calcineurin inhibitor tacrolimus (FK506) prevents hyphal growth of Mucor spp. Furthermore, the cAMPdependent protein kinase A (PKA) is involved in the dimorphic transition as in other dimorphic fungi (Candida species, Cryptococcus neoformans, Cryptococcus gattii, and Aspergillus fumigatus). The yeast-locked mutants were less virulent than wild-type strains, suggesting that hyphae are more virulent or the dimorphic switch is important for the pathogenicity of this fungus. Finally, the authors showed that calcineurin participates in hyphal polarity development and spore size dimorphism. Calcineurin is a promising drug target against many fungal pathogens with dimorphic growth (Table 1).

Mucoralean hyphae are often heavy and have a bigger diameter than in Ascomycota. Hyphae diameter and size determine the efficacy of phagocytosis by macrophages. They differ in cell wall composition as well, and they have less glucan and more chitin compared with Ascomycota. This change in biochemistry determines antifungal susceptibility/ resistance, because most antifungal drugs target either the cell wall machinery or components. They are galactomannannegative; thus, serum tests based on this feature can differentiate between Ascomycota and Zygomycota, but only to confirm the presence of Ascomycota and they provide no information about the presence/absence of Zygomycota. Zygomycota are resistant to most of the newer antifungals, such as voriconazole and echinocandins, which are very efficient against Candida and Aspergillus mycoses. The three 
Table 1 Summary of differentiating features among filamentous fungi

\begin{tabular}{lll}
\hline Character & Ascomycota (e.g., Aspergillus) & Zygomycota (e.g., Mucor) \\
\hline Spores & Hydrophobic spores (conidia), ascospores & Dry and wet sporangiospores, zygospores \\
Hyphae & Narrow $(2-3 \mu \mathrm{m})$, septate, branching in different angles & Broad (6-16 $\mu$ m), coenocytic, orthogonal ramifications \\
Cell wall composition & More glucan & More chitin \\
& Galactomannan present & Galactomannan absent \\
\hline
\end{tabular}

orders of Zygomycota infecting humans have different susceptibility/resistance patterns.

In vitro studies revealed the potential for biofilm formation for $R$. oryzae, L. corymbifera, and R. pusillus, but not for A. elegans [25]. The biofilm matrix is formed with glucosamine as the dominant dry component (Table 2).

Rhizopus oryzae is claimed to possess extraordinary genome plasticity owing to a whole genome duplication, which resulted in an elevated number of genes, including those involved in host-pathogen interactions [6, 26]. Currently, more Zygomycota genomes have been sequenced, including Lichtheimia hyalospora, Mucor circinelloides, Mortierella elongata, Rhizopus microsporus, and Conidiobolus coronatus, which will enable comparative studies and accelerated screening of drug targets. Comparative analyses will facilitate the identification of conserved components of the fungal cell machinery. Based on the sole gene count and genome size comparisons, it is clear that Rhizopus oryzae is an exception regarding the number of genes in the whole collection of currently sequenced Zygomycetes, with the average gene number of 11 thousand genes. Table 3 lists the estimated genome sizes and predicted gene numbers for Zygomycetes present in the Joint Genome Institute (JGI) sequencing center database.

\section{Systematics}

Fungal systematics have been recently reorganized [27], which resulted in temporary chaos in the nomenclature. A revised taxonomic classification has been introduced for several of the human and animal fungal pathogens that are also

Table 2 Summary of differentiating features of entomophthoromycosis and mucormycosis

\begin{tabular}{lll}
\hline Feature & Mucormycosis & Entomophthoromycosis \\
\hline Progression of the infection & Rapidly invasive & Local \\
Immune reaction & Acute & Chronic \\
Host immunity & Compromised & Competent \\
Localization & Systemic & Cutaneous, soft tissue \\
Lipase & - & + \\
Keratin degradation & - & + \\
Thermotolerance & + & - \\
\hline
\end{tabular}

part of the previous Zygomycota phylum [12-14]. These changes in nomenclature should better reflect biological differences among taxa. A reliable source of valid nomenclature are the Index Fungorum and MycoBank. Zygomycota themselves do not currently constitute a valid taxon; instead, more subphyla and orders are proposed.

Only 3 of the 13 orders of known Zygomycetes, namely the Mucorales, the Mortierellales, and the Entomophthorales, harbor animal and human pathogens [28]. However, Mortierella wolfii is a cattle pathogen, the documentation of human infections is scarce and no cases have been described since 2000 . Consequently, we will focus only on Mucorales and Entomophthorales infections, called mucormycosis and entomophthoromycosis respectively). Supplementary Table S1 lists the Mucoromycotina, Mortierellomycotina, and Entomophoromycotina that are involved in human infections with synonymic names and examples of case reports. The mucoromycotina group contains most of the human pathogenic Zygomycota.

Some taxa have been recently revised, deemed to be species complex and consequently divided into more taxa. Among them, Apophysomyces spp. now account for four taxa with differences in spore shape and ITS sequence levels [29]. Owing to the introduction of separate taxa in 2010, most reports in the literature refer to A. elegans. However, future work should refer to the newest nomenclature. A similar pattern involves Saksenaea vasiformis, which is now considered a species

Table 3 Currently sequenced Zygomycota genomes stored by the Joint Genome Institute (JGI)

\begin{tabular}{llc}
\hline Organism and project name & $\begin{array}{l}\text { Genome } \\
\text { size }\end{array}$ & $\begin{array}{l}\text { Number } \\
\text { of genes }\end{array}$ \\
\hline Coemansia reversa NRRL 1564 v1.0 & $21,838,014$ & 7,347 \\
Umbelopsis ramanniana AG \# v1.0 & $23,077,072$ & 9,931 \\
Conidiobolus coronatus NRRL28638 v1.0 & $39,903,661$ & 10,635 \\
Rhizopus microsporus var. microsporus v1.0 & $25,972,395$ & 10,905 \\
Mucor circinelloides CBS277.49 v2.0 & $36,587,022$ & 11,719 \\
Lichtheimia hyalospora v1.0 & $33,282,407$ & 12,062 \\
Gonapodya prolifera v1.0 & $48,794,828$ & 13,902 \\
Mortierella elongata v1.0 & $49,959,475$ & 14,964 \\
Phycomyces blakesleeanus NRRL1555 v2.0 & $53,939,167$ & 16,528 \\
Rhizopus oryzae $99-880$ from Broad & $46,087,117$ & 17,467 \\
\hline
\end{tabular}


complex and in consequence was split into more taxa characterized by spore shapes [30]. Among the most characteristic pathogenic Mucorales Rhizomucor variabilis was moved to the Mucor genus based on molecular characteristic and renamed Mucor irregularis [31]. Other taxa suspected to be species complex were confirmed as true species. Rhizopus microsporus was revised as a single species and its varieties might be just environmental variants. Importantly, foodborne, environmental and clinical strains are indistinguishable [32]. This observation supports the opportunistic character of mucormycoses

\section{Host-fungus interaction}

Key factors involved in fungal infections seem to be shared among distantly related fungi pathogenic to different hosts $[24,33]$.

The respiratory tract is the main entrance for fungi, among them Zygomycetes. Inhaled aerosolized spores are removed by the movements of ciliated epithelial cells. If some manage to overcome this barrier the alveolar macrophages phagocytose and destroy most spores. Healthy gastrointestinal tract and skin are good barriers to Zygomycetes. It is not surprising that most skin infections are a consequence of direct inoculation due to severe trauma. Gastrointestinal infections are most common in neonates, who have not yet developed proper immune mechanisms.

The description of host pathogen interactions at a molecular level shows differences in the mechanisms of aspergillosis and mucormycosis, including host immune response and susceptibility to macrophage-induced hyphal damage [34]. Furthermore, biological features of the causing agent determine the location and progress of the infection, leading to a more localized infection in entomophthoromycosis and a progressive and potentially disseminated infection in mucormycosis. Entomophthorales specialized in cutin degradation exert keratinolytic enzymes; as a consequence entomophthoromycoses are usually superficial and gastrointestinal infections. In contrast to Entomophthorales, human-infecting Mucorales are usually thermo-tolerant, which makes them able to invade internal body parts and form a chronic infection.

The interplay between pathogens and hosts varies among fungal agents and the host condition. However, some general trends can be drawn. Most of the mechanisms are known from animal data; the latter should be considered with caution as the inflammatory reaction is different in rodents and apes. The role of the immune system in preventing and eliminating fungal infections involves an inflammatory reaction. Inflammation triggered by Zygomycota is usually less visible than in aspergillosis. Ascomycota are recognized by both TRL2 and TRL4 receptors, whereas Zygomycota are recognized solely by TLR2 receptors [34]. There is another major difference compared with aspergillosis regarding the involvement of $\mathrm{T}$ lymphocytes. This is because innate immunity is indispensable in fighting a Zygomycota infection and the acquired immunity involvement is not that pronounced. However, Mucorales-specific T cells and NK cells can be found both in patients and in healthy individuals. These findings pave the way for potential diagnostic tests and adoptive immunotherapy [35].

One of the most characteristic features of zygomycoses is their occurrence in diabetic patients. Some aspects of the interplay between the fungus and diabetic patients has been revealed at a molecular level. During the infection $R$. oryzae binds to GRP78 receptors [36, 37]. The expression of GRP78 receptor coding genes is affected by acidosis and by iron and glucose levels, which are observed in diabetic patients (high blood sugar levels and available iron). In such a scenario $R$. oryzae become more resistant to neutrophils, which are susceptible to low $\mathrm{pH}$ conditions. One taxon may produce hyphae and spores of variable size. Phagocyte-induced damage is related to target mass; bigger hyphae are harder to phagocytose. Schmidt and colleagues [38] demonstrated that both unstimulated and IL-2-prestimulated human NK cells damage Rhizopus oryzae hyphae, but do not affect resting conidia. They concluded that the damage of the fungus is mediated, at least in part, by perforin. $R$. oryzae hyphae decrease the secretion of immunoregulatory molecules by NK cells, such as IFN- $\gamma$ and RANTES (regulated on activation, normal T-cell expressed and secreted), indicating an immunosuppressive effect of the fungus.

A study on the activity of human polymorphonuclear leukocytes (PMNLs) against R. oryzae, R. microsporus, and L. corymbifera revealed that interferon (IFN)-gamma and granulocyte-macrophage colony-stimulating factor (GM$\mathrm{CSF}$ ) augment the hyphal damage of all three zygomycetes. Additionally, this effect was more pronounced against L. corymbifera than against both Rhizopus species [39].

Genus-specific patterns could be drawn from pulled data from multiple infections. It is currently known that Cunninghammella is more aggressive than Lichtheimia in diabetes patients [34]. It induces low TNF $\alpha$ levels and is resistant to hyphae damage by macrophages. In rare cases it can invade an immunocompetent host [40], which suggests some of the specific properties of Cunninghammella compared with other Mucorales. Cunninghammella infections have higher mortality rates than other, more common infections [8].

\section{Epidemiology}

\section{Risk factors}

There are several risk factors associated with opportunistic fungal infections, among them zygomycoses. Diabetic 
ketoacidosis [8, 41], treatment with corticosteroids [42, 43], deferoxamine in patients on dialysis [44], and immunosuppressive drugs [36] enhance susceptibility to developing zygomycosis. Neutropenia [36, 45], malnutrition [46], cytomegalovirus infection [47], and extended wounds/burns [48, 49] are also predisposing conditions associated with zygomycosis.

According to the main reviews by Roilides et al. [34] and Ibrahim et al. [36] neutropenia, diabetes with blood hyperglycemia and low $\mathrm{pH}, \mathrm{Fe}$ overload, corticosteroid therapy, and direct inoculation as a result of trauma are the main risk factors. Neutropenic patients are at increased risk, whereas patients with AIDS are not. This is because T lymphocytes are not key players in fighting against Zygomycota infection. The phagocytes provide antifungal activity via oxidative metabolites and defensins [36]. Immunosuppression leading to neutropenia encountered in transplant recipients renders them susceptible to zygomycosis. Corticosteroid therapy also influences neutrophils and their activity against fungi.

It has been found that [8] diabetic patients are exceptionally susceptible to sinusitis infections. Diabetic patients have an altered innate immunity with reduced chemotaxis of PMNLs, impaired transmission through the vascular endothelium, and reduced superoxide production [50,51].

With regard to Fe overload, iron is indispensable for vital life processes and as a such is a limiting factor. Pathogens developed many traits to acquire iron from the host and Zygomycetes are no an exception. Deferoxamine therapy is suspected to facilitate Zygomycota infection by making iron available.

Healthy skin provides an efficient barrier against Mucorales; thus, skin trauma provides a risk of developing mucormycosis [36]. This condition is favorable for fastgrowing opportunistic organisms. Contact with soil, food, and water containing fungi can be detrimental to either burned or severely wounded patients (Table 4).
Sources and routes of infection

Mucorales are ubiquitous in the environment. They may be present in rotten organic debris (foods, fruits, vegetables, seeds and nuts, plants). Sporangiospores are easily aerosolized and dispersed in the air, which may be the source of infection by inhalation of spores. However, the occurrence of sporangiospores in indoor and outdoor air is less than that of conidia of aspergilli and other molds.

There are three main routes of infection for Zygomycota. The most common is via the respiratory system, i.e., the sinuses and lungs. Wards where there are patients with neutropenia and other risk factors for invasive fungal infection should undergo air-conditioning monitoring, and plants, which are potential sources of fungal growth and sporulation, are not permitted there.

Published data describing the levels of zygomycete sporangiospores in outdoor and indoor air in relation to seasonal variation are scarce. It was suggested on the basis of two articles from the Near East and analyses of the seasonal presence of sporangiospores in outdoor air that mucormycosis may occur seasonally at the end of the summer and in the fall, when the weather is warm and humid [21].

The second route of infection is via direct inoculation of fungal propagules into the human body. It can be iatrogenic or commonly acquired. Nosocomial infection can be due to contaminated medical devices, e.g., ostomy pouching systems, adhesive bandage, wooden tongue depressors, subcutaneous insulin infusion pump, peritoneal dialysis, intravascular devices, or contamination during medical procedures, e.g., dental extraction and local anesthesia, intramuscular injection of corticosteroids, vitamins and anticoagulants, nasal packing, contamination of grafts, and during transplantation. Commonly acquired inoculation of zygomycota fungi may occur as a result of traffic accidents, burns when the contaminated soil, water, plant debris among others, comes into contact with

Table 4 Infection prevalence and its main features [8, 41, 52, 53]

\begin{tabular}{|c|c|c|c|}
\hline $\begin{array}{l}\text { Underlying disease/ } \\
\text { condition }\end{array}$ & $\begin{array}{l}\text { Percent of patients } \\
\text { with zygomycosis }\end{array}$ & $\begin{array}{l}\text { The most common } \\
\text { form of infection }\end{array}$ & Mechanism and predisposing factors \\
\hline Hematological malignancy & $11-17$ & Pulmonary; disseminated & Neutropenia, voriconazole prophylaxis \\
\hline HSCT recipients & $1,2-5$ & Rhinocerebral; pulmonary & $\begin{array}{l}\text { Steroid prophylaxis for GvsH disease, neutropenia, } \\
\text { voriconazole prophylaxis }\end{array}$ \\
\hline Diabetes mellitus & $17-36(74)$ & Rhinocerebral, sinus & $\begin{array}{l}\text { Acidosis - increasing iron level acidosis and } \\
\text { hyperglycemia - has a negative impact on } \\
\text { neutrophil chemotaxins and phagocytic activity }\end{array}$ \\
\hline Solid organ transplantation & $(0.6) 7-13,23$ & Pulmonary, liver, and other transplant organ & Transplant contamination \\
\hline Deferoxamine therapy & $1-6$ & Disseminated, pulmonary & Increasing iron level \\
\hline Burns, trauma in accident & $13-20$ & $\begin{array}{l}\text { Cutaneous, even } 40 \% \text { of infections are } \\
\text { disseminated }\end{array}$ & Disruption of skin barrier (spore inoculation) \\
\hline Malnourished patients & 3 & Gastrointestinal & Digestion of the fungi \\
\hline (Premature) neonates & $3-21$ & Gastrointestinal & \\
\hline
\end{tabular}


injured skin and tissues. Infection can also occur through insect bites. This route of infections is dominant in healthy patients. The less common type of Zygomycota infection is via the oral route [51].

Among nosocomial sources of infection there are reported cases of contaminated biomedical devices and building constructions. In a review of 169 cases by Rammaert and colleagues [51] a variety of sources of infections are listed, among them grafts, ostomy bags, adhesive bandages, water, wooden tongue depressors, dental extraction and local anesthesia, blood glucose self-monitoring equipment, subcutaneous insulin infusion pump, peritoneal dialysis, intravascular devices, intramuscular injection of corticosteroids and vitamins, and nasal packing. Neonatalogical, hematological, transplantation and burn units should monitor their conditions to ensure patients' well-being.

Special focus should be directed toward donor-derived filamentous fungal infections in transplant recipients [54], which have a fatal outcome [51]. Environmental sources of infection are dominant in healthy patients with a challenged skin barrier - after trauma (car accident, burns), among them soil/decaying organic matter [55] and water [56] should be considered. Even plant pots in hospitals can be a source of infection for immunosuppressed patients.

\section{Prevalence}

In the general population, zygomycosis is a very rare disease. Orphanet (the Orpha number, i.e., the Orphanet identifier for zygomycosis is 73263) classified it as a rare infectious disease; however, its prevalence is not known. There are several estimations of the incidence of zygomycosis/mucormycosis, showing some discrepancies. A more accurate assessment of zygomycosis prevalence is currently not feasible owing to incomplete identification and documentation. However, some best practice approaches have been introduced, like the Working Group on Zygomycetes by the International Society for Human and Animal Mycology (ISHAM). Rees and colleagues [57] estimated the incidence of mucormycosis to be 1.7 cases per million people per year, analyzing a populationbased study in the USA performed in the 1990s. A Spanish, multicenter, population-based study, based on 6 diagnosed cases of zygomycosis in Spain in 2005 [58], showed that the incidence of zygomycosis was 0.43 out of $1,000,000$ inhabitants per year and 0.62 out of 100,000 hospital admissions. That gives $430-1,700$ cases per million per year worldwide. However, Brown [59] estimated that more than 10,000 lifethreatening cases of mucormycosis occur worldwide per year, with 30-90\% mortality rate within infected persons.

Postmortem prevalence evaluation shows that mucormycosis is 10 - to 50 -fold less frequent than both candidiasis and aspergillosis, with a frequency of $1-5$ cases per 10,000 autopsies [60-62]. Zygomycosis represents 8.3-13\% of all fungal infections encountered at autopsy in high-risk patients [52].

Males are more likely to be affected by zygomycosis than women $(58-68 \%$ of cases $[8,63-65])$. This fact can be explained by the incidence of hematological malignancies (HM) (and most cancers) being generally lower in women than in men. The smaller number of cancers in women is a well-documented phenomenon and could be in part the result of a lower exposure to environmental and occupational risk factors in women than in men [66, 67]. Omoti et al. [68] reports that $\mathrm{HM}$ affects male $(56 \%)$ and adult ( $>15$ years; $83 \%$ ) patients more often. However, Skiada et al. found that there is no predilection as regards sex in cutaneous zygomycosis, which affected generally healthy subjects [69].

In 2011, a large prospective multinational European study based on 230 patients with zygomycosis showed that the most common predisposing conditions were hematological malignancies (44\%), trauma (17\%), DM (17\%), and hematopoietic SCT (9\%) [65].

\section{Hematological malignancies}

Patients with hematological malignancies (HM) either with or without hematopoietic stem cell transplantation (HSCT) constitute the most commonly infected group. They account for up to $44 \%$ of all cases of zygomycosis [45, 52].

The retrospective cohort study was conducted in the hematology wards of either tertiary care centers or university hospitals located throughout Italy, between 1999 and 2003. Five hundred and thirty-eight proven or probable invasive fungal infections (IFI) in 11,802 patients with newly diagnosed hematology malignancies (AML, ALL, CML, CLL, NHL, HD, and $\mathrm{MM}$ ) were documented. The overall incidence of IFI was $4.6 \%$. Zygomycetes in this study occur in 1.2 out of 1,000 $(0.12 \%)$ HM patients (most frequently among AML and ALL patients $-0.3 \%$ ) with $64.3 \%$ mortality rate (attributable mortality rate $0.08 \%$ ). In this study zygomycetes were the fourth most common agents of IFI following Aspergillus, Candida, and Fusarium) [7].

In another study conducted in Southern Italy over 18 months, in 589 patients (475 adults and 114 pediatrics) with newly diagnosed HM (AML, NHL, ALL, CLL, MM), 27 episodes of IFIs were documented [70]. The overall incidence was $4.6 \%$. Of the 27 documented IFIs, 16 were caused by yeasts (13 in adult patients and 3 in pediatric patients) and 11 by filamentous fungi (all in adult patients). A total of 11 mold infections $(40.7 \%, 10$ aspergillosis and 1 zygomycoses) were reported only in adult patients (incidence $2.3 \%$ ). Occurrence of zygomycosis was slightly higher than observed in the study by Pagano et al. [7] - 1.6 out of 1,000 vs 1.2 out of $1,000 \mathrm{HM}$ patients.

Neofytos and colleagues [71] performed a multicenter, prospective, observational study to assess the epidemiological 
characters and outcomes of invasive fungal infection (IFI) in hematopoietic stem cell transplant (HSCT) recipients in North America. In this study were included 234 adult HSCT recipients with a total of 250 cases of IFI. The most frequent was invasive aspergillosis (59.2\%) followed by invasive candidiasis $(24.8 \%)$ and zygomycosis $(7.2 \%)$, and other molds $(6.8 \%)$ [72]. In 178 autopsies of HSCT recipients (45.1\%) infectious etiologies were found to contribute to the cause of death. Fungal infections were found in 93 cases $(23.5 \%)$. Among fungal infections caused by cultivable species the most common was Aspergillus spp. (44.6\%) followed by Candida (33.9\%), Zygomycota (7.1 \%), and Pneumocystis (7.1\%).

These data suggest that zygomycetes infection occurs in $1.7 \%$ of patients with HSCT recipients (17 cases of zygomycosis per 1,000 HSCT recipients).

\section{Diabetes}

Another risk factor is diabetes mellitus. Zygomycosis occurs mainly in patients with uncontrolled diabetes, especially those with ketoacidosis. In 2012 the WHO estimated the number of diabetic patients to 220 million (current estimates from the WHO Fact sheet no. 312, updated March 2013: 347 million people worldwide have diabetes [73]). Zygomycoses are associated with DM in 17-36 \% of cases. If we take into account estimates that worldwide there are 10,000 patients with zygomycosis, which gives us 0.9-1.8 cases of zygomycosis per 100,000 diabetic patients (approximately 0.0009$0.0018 \%$ ).

The problem of zygomycosis in diabetic patients is associated with poverty and malnutrition, for example, in India where uncontrolled DM was the most commonly found predisposing factor in $74 \%(n=131)$ of the 178 cases of zygomycosis identified between 2000 and 2004 [74]. In contrast to France, where DM was associated with only $9 \%$ of 531 cases of zygomycosis reported between 1997 and 2006 [63].

\section{Solid organ transplantation}

Zygomycoses have been reported from different organs such as kidney, liver, heart and lung transplantations. Zygomycosis was generally considered to be a rare complication in solid organ transplant recipients [75]. Incidence of zygomycosis in solid organ transplant recipients is estimated to range from 0.4 to $16 \%$ depending on the procedure and geographical area [63]. The most recent multicenter prospective study conducted in the USA found that out of 16,457 transplant patients 12 had Mucorales infection $(0.07 \%)$; among organ recipients in particular, Mucorales infection occurred as follows: lung 2 out of $1,179(0.17 \%)$, liver 7 out of $4,361(0.16 \%)$, kidney 3 out of $8,494(0.03 \%)$; in the pancreas $(1,174)$, heart $(1,159)$, and small bowel (69) there were no zygomycosis infections [5].

Although zygomycoses are relatively rare they are characterized by a severe course and high mortality rate. Early diagnosis of the infection is still a challenge and the demand for better diagnosis is growing with the increasing number of reported cases. The latter is possibly caused by a species shift resulting from the common prophylaxis of fungal infection with azoles (fluconazole and voriconazole) in at-risk wards. Zygomycota are not susceptible to azoles, except for posaconazole.

Clinical manifestations

There are five main clinical manifestations of Zygomycosis [52]: rhinocerebral, pulmonary, gastrointestinal, cutaneous, and disseminated. Spellberg and colleagues listed six groups of miscellaneous mucormycosis presentation in which they included brain involvement without sinus infection, endocarditis, pyelonephritis, bone infection, external otitis, etc. [53].

Among patients from the group at risk of zygomycosis, the most common manifestation is rhino-(orbital)-cerebral (33$49 \%$ ), followed by cutaneous (10-16\%), pulmonary (10$11 \%$ ), disseminated (6-12\%), and gastrointestinal (2-11\%). In immunocompetent/otherwise healthy patients the most representative clinical form was the cutaneous/subcutaneous form (42.5\% of patients), followed by the rhino-orbitocerebral (38\%) and genitourinary (8.5\%), disseminated, and pulmonary infections [76].

\section{Rhinocerebral mucormycosis}

Rhinocerebral mucormycosis is the most common form present in both neutropenic hematological and diabetic patients. Initial symptoms are nonspecific, involving headaches, altered mental status, fever, and eye syndrome, lacrimation, irritation, or periorbital anesthesia. Unilateral vision disturbance and further changes involving ptosis, proptosis or loss of extraocular muscle function are signs of the progressing infection toward the retro-orbital region or the central nervous system (CNS). Necrotic black lesions on the hard palate, necrotic turbinates, and septum perforation should be carefully inspected. The radiographic image of the infection can be mimicked by bacterial and other fungal infections as well as tumors. Scheckenbach and colleagues [77] reported that initial CT scanning was not informative and most manifestations were not specific; only histopathology provided sufficient data to establish a reliable diagnosis. Proper management of the primary disease is essential for a favorable outcome. 


\section{Pulmonary mucormycosis}

Pulmonary mucormycosis usually occurs in patients with profound neutropenia, hematological malignancies, those on corticosteroid therapy or those with diabetes. The symptoms are not specific and involve fever, chest pain, and cough. Neutropenia and coagulation dysfunctions make tissue collection inadvisable in some cases. Radiographic or CT scans showing multiple $(>10)$ nodules or pleural effusions can be a sign of fungal infection. Although other mycoses, bacterial infections or malignant invasions should be considered.

\section{Gastrointestinal mucormycosis}

Gastrointestinal mucormycosis is a very rare form of infection. It is associated with severe malnutrition and premature birth. The infection is thought to be a consequence of the ingestion of fungi. The symptoms including fever, pain, vomiting, diarrhea, and constipation are nonspecific. The infection may lead to ischemic infarction and ulceration. The stomach, terminal ileum, and colon are the most common sites; however, any part of the gastrointestinal tract can be colonized. The diagnosis requires direct examination and biopsy, and is often only performed at autopsy.

\section{Cutaneous (skin) mucormycosis or entomophthoromycosis}

Cutaneous infection can be either primary or secondary. A primary infection develops in patients who have suffered burns or other trauma. The infection is caused by direct inoculation during an accident or can be nosocomial. The disease manifestation involves erythema, pus, abscess formation, tissue swelling, necrosis, and pain in the infected area. The skin appears red and indurated and the necrosis can be observed as black eschars. The tissue necrosis can progress to gangrenous cellulitis.

Cutaneous infection can be a secondary locus in patients with disseminated infection from the respiratory tract. Cutaneous mucormycosis has been reported in diabetic patients.

\section{Disseminated mucormycosis}

This form of mucormycosis is the hardest to control and constitutes the greatest threat to the patient. When two or more noncontiguous organs are involved an infection can be considered disseminated. These often include lung and CNS colonization, with the lung often being the primary infection site. The involvement of the lung and skin is a sign of a higher risk of CNS invasion as well. Since the disseminated form often involves CNS colonization, the disease can manifest as changes in the mental status. Other internal organs can be secondarily invaded during colonization, among others the spleen, liver, and even the heart, leading to pain in the infected organ.

\section{Pediatric cases}

Zaoutis and colleagues consider that pediatric cases should be treated as a separate category [78, 79]. There is limited information about zygomycoses in children. Infection in children is different: they tolerate more intensive treatment and GI tract infections are fatal, being the third most common manifestations of zycomycoses in neonates.

\section{Diagnosis of Zygomycota infections}

Zygomycosis is still a challenge for diagnostics, especially considering that early diagnosis is the best drug in zygomycoses. The diagnosis relies on clinical findings, risk factor analysis, histopathology, and culture samples inspection. The clinical signs vary with the form and stage of the infection. In rhinocerebral zygmycosis, classic clinical features include facial swelling, with ocular involvement. Patients often report facial and eye pain, proptosis, and visual disturbances that are signs of the involvement orbital structures (muscles, nerves, and vessels). Black necrotic lesions can also occur, for example, on the hard palate. Pulmonary zygomycosis manifests with nonspecific symptoms such as fever, cough, and dyspnea; when fungi invade vessels hemoptysis may also occur. Radiographic findings can be vague and often overlap with other mold infections. The presentation of pulmonary zygomycosis often resembles that of an invasive aspergillosis in severely immunocompromised patients, for example, HSCT recipients. Comparison of the CT imaging features of pulmonary zygomycosis and invasive pulmonary aspergillosis has shown that the presence of multiple nodules $(>10)$ and, to a lesser degree, the presence of pleural effusions, favored the presence of the former diseases. Additionally, micronodules seen on the initial CT scans were more commonly observed in patients with pulmonary zygomycosis [80]. Gastrointestinal zygomycosis may occur in patients with severe malnutrition. The clinical picture mimics intra-abdominal abscess. Unfortunately, the diagnosis is often made at autopsy. Differentiation with other fungal infection is very important because Zygomycota are resistant to voriconazole, a drug successfully used in the treatment of invasive aspergillosis.

The diagnosis can be performed on several levels:

1. Identification of an invasive mold infection

2. Distinguishing between Ascomycota and Zygomycota

3. Species/genus identification 
Diagnostic imaging

Diagnostic imaging is useful in the early diagnosis of rhinocerebral, non-enhanced paranasal sinuses or lung lesions. This method allows the preliminary recognition of probable Mucorales infection. Computed tomography (CT) has a higher sensitivity and allows an earlier diagnosis than the classical radiographic techniques. CT scans can reveal lesions caused by angioinvasive fungi not visible on conventional radiographs and before other clinical manifestations [81]. CT gives the opportunity to show mucosal thickening and early bone destruction. Lesions that could be revealed on lung CT scans are nodules, halo signs, reverse halo signs, cavities, wedge-shaped infiltrates, pleural effusions, and angioinvasion of molds. These need to be confirmed by biopsy and molecular or culture-based methods. The presence of pulmonary infiltrates in neutropenic patients is already a sign of angioinvasion, necrosis, thrombosis, hemorrhage, and edema. These can be the first observable signs of angioinvasion and systemic fungal infection. CT imaging of infected organs often shows limited inflammation around hyphae compared with Aspergillus. The observed lesions can change in the course of infection, but are not specific enough to reliably differentiate among causing agents like Aspergillus, Scedosporium, Fusarium, Mucorales, and mixed infections. The major disadvantage of using CT is the exposure of patients to a high dose of radiation. The radiation exposure associated with CT scans limits their routine or serial usage.

Another imaging technique used in diagnostics is MRI. This method is mandatory for assessing extension into the cavernous sinus and identifying cerebral involvement. Lesions that can be revealed by MRI are orbital and intradural expansion, cavernous sinus thrombosis, or thrombosis or aneurysm of the internal carotid artery.

Positron emission tomography (PET) has the highest sensitivity among diagnostic imaging methods. This technique can detect small infectious foci before the onset of the anatomical abnormalities assessed by conventional radiology tools. PET is not recommended for the evaluation of cerebral involvement and in diabetic patients control of glycemia is also required.

Preliminary diagnosis based on the above-described techniques needs to be confirmed by biopsy and molecular or culture-based methods.

\section{Direct examination and culture-based methods}

Direct examination can provide only limited information on the causative agent, but in the absence of the quick diagnostic test, biopsy with histopathological assessment remains a crucial method in the diagnosis of zygomycosis. In tissue materials zygomycosis can be recognized by the presence of broad, nonseptate hyphae, invading tissue and causing necrosis, vascular invasion, and thrombosis. The hyphae of Zygomycota branch at a right angle, as opposed to other fungi such as Aspergillus, whose hyphae branch at a slight angle. However, they can be easily overlooked in tissue samples stained with nonfungal staining. Many infections are diagnosed definitively only at autopsy.

To diagnose mucormycosis different specimens are taken that are adequate to the location of the ongoing process of infection. For the rhinocerebral form the appropriate samples are as follows: sinus aspirates, tissue specimens from the affected area, and also scraping of the nasal mucosa. In the case of pulmonary infection deep samples of tissues and bronchoalveolar lavage (BAL) with flexible fiber optic bronchoscopy can be obtained. Sputum testing is less sensitive, especially in non-neutropenic patients. CT-guided biopsy can also be performed in the case of negative BAL findings [82].

The biopsy of the lesion is necessary to establish the diagnosis of cutaneous mucormycosis. The biopsy specimen should be taken from the center of the lesion and include subcutaneous fat, because molds frequently invade blood vessels of the dermis and subcutis, resulting in an ischemic cone at the skin surface [83]. Impression smears from the wound edges may also help with the diagnosis [69].

Culture is useful for identification of etiological agents and antifungal drug susceptibility testing. Mucorales are fast growing molds; thus, 24-h incubation on fungal media like Sabouraud agar and malt extract agar at $25-37{ }^{\circ} \mathrm{C}$ usually suffices for colony formation. A positive culture in a patient with no clinical symptoms should be interpreted with caution because of the possibility of environmental contamination. Besides the classic morphological identification of molds there are some metabolic markers that are important for species/genus identification, such as the ability to grow within certain temperature ranges and assimilation of different compounds as a sole carbon source.

Human pathogenic Mucorales differ with regard to carbon source utilization patterns [84], which could be used for species identification, either directly in culture-dependent assays or for the development of metabolite-based approaches. There are limited data on species differences in pathology/ treatment owing to the very recent establishment of some of the aforementioned new taxa. Differential carbon source usage was reported for Apophysomyces with negative results for assimilation of D-galactose and other sugars [29] and positive for the members of six other genera of pathogenic Zygomycota, i.e., Cunninghamella, Lichtheimia, Mucor, Rhizopus, Rhizomucor, and Syncephalastrum [84]. Such differences might be used to develop identification tests.

Species identification can be confirmed by molecular methods based on the sequencing of a standard PCR product obtained with universal fungal ITS primers on DNA extracted from a culture, enabling reliable order/species level identification of the infecting fungus. In laboratories equipped with 
reference libraries techniques such as MALDI-TOF might also be possible from culture samples.

Culture-independent methods: molecular diagnosis

Currently, there are no circulating antigen detection tests available. The promising 1,3 beta-D-glucan tests are commonly found to be negative in Mucorales. A double galactomannan and 1,3 beta-D-glucan test can be of help in excluding invasive aspergillosis or a double infection by Aspergillus and Mucorales. PCR-based tests of blood samples are not yet available. Consequently biological samples of the infected sites should be collected for histopathology and culture. Invasive diagnostic biopsy of infected tissue in sinus and lung infections should be performed. Blood and cerebrospinal fluid are usually culture-negative.

Culture-independent molecular techniques are being developed: some are complex and laborious [85] and others require sophisticated equipment and reference datasets. Zhao and colleagues describe an assay based on a combination of broad-range PCR amplification and reverse line blot hybridization (PCR/RLB) that enabled them to identify fungi from tissue samples in $7 \mathrm{~h}$ [85] with high specificity (no falsepositives) and false-negatives solely for fungi not included in the reference. Additionally, their method works for concentrations of $1.8 \times 10^{-3} \mathrm{ng} / \mu \mathrm{l}$ of genomic DNA.

More specific and sensitive molecular markers and secondary metabolite identification methods are still being developed.

MALDI-TOF diagnostics are currently based on reference datasets and require cultivation; however, a development of serum-based profiles is expected in the near future.

\section{Treatment}

According to the largest meta-analysis performed by Roden and colleagues [8], lack of treatment had a fatal outcome, with only $3 \%$ survival. A double treatment consisting of antifungal therapy combined with surgical intervention was most successful, leading to the survival of $70 \%$ of patients.

Early diagnosis is the key factor for a successful outcome [8]. This is followed by surgical debridement and antifungal therapy. Necrotic tissue resulting from disease progression may require repeated excision as it prevents antifungal agent penetration [45]. Amphotericin B is the main drug used in the treatment of mucormycosis, entomophthoromycosis and mortierellomycosis. High therapeutic dosage should be achieved as soon as possible. Lipid formulations tend to be better tolerated, limiting the nephrotoxicity [86]. Currently, no other drug displays comparable activity against all three groups of fungi. The main antifungal drugs belong to five different groups: echinocandins, azoles, polyenes, allylamines, and pyrimidine analogs. The echinocandins (caspofungin, micafungin, and anidulafungin) inhibit the synthesis of 1,3- $\beta$-D-glucan, an essential component of the fungal cell wall. Azoles (fluconazole, hexaconazole, isavuconazole, itraconazole, posaconazole, ravuconazole, voriconazole) are lanosterol 14 alpha-demethylase inhibitors. Polyenes bind ergosterol, a cell membrane component (amphotericin B, nystatin, and natamycin). Allylamines inhibit squalene monooxygenase; among them only terbinafine is used against fungi. The main antifungal pyrimidine analog and thymidylate synthase inhibitor is flucytosine.

An evaluation of amphotericin B, ketoconazole, fluconazole, intraconazole, voriconazole, posaconazole, caspofungin, and flucytosine activity against most of the human pathogenic Mucorales: Rhizopus sp. R. arrhizus, R. microsporus var. rhizopodiformis, $R$. microsporus var. micorsporus, Mucor sp. M. circinelloides group, Rhizomucor sp., Absidia sp. Absidia corymbifera, and Cunninghamella sp. Apophysomyces elegans revealed that posaconazole is the second most promising drug [6]. A recent report from the 3rd European Conference on Infections in Leukemia (ECIL 3) provides a detailed guideline regarding the diagnosis and treatment and lists as yet unanswered questions [45].

\section{Amphotericin B}

Amphotericin B deoxycholate was introduced more than 50 years ago and become the gold standard of therapy for invasive mycoses $[86,87]$. It has a broad spectrum activity against most fungal agents and serves as a reference in searches for novel antifungal drugs. The administration of AMB causes severe side effects, among them high nephrotoxicity, which leads to the development of less nephrotoxic lipid formulations. The latter can be administered in higher doses than the native drug. Comparative trials are performed between the more common liposomal amphotericin B (LAmB) and amphotericin B colloidal dispersion (ABCD), which is less frequently studied.

\section{Posaconazole}

Posaconazole is an exception among azoles, which display either moderate or no activity against most of the strains tested. Mucorales are in general susceptible to amphotericin $\mathrm{B}$, but display variable response to posaconazole. A recent report from the SEIFEM and FUNGISCOPE [7, 88] registries evaluated the outcome of combined lipid formulation of amphotericin B (LAmpB) posaconazole (POS) therapy of invasive mucormycosis in 32 patients [88]. This evaluation was essential because of the limited number of cases in previous clinical reports and inconclusive previous studies that reported synergistic effects in vitro and no improvement relative to LAmpB monotherapy in mouse models. Pagano and colleagues conclude that a combined therapy should be 
considered in severe cases of invasive mucormycosis. Additionally, it is recommended to consider prophylaxis with posaconazole in at-risk groups. It is a broad spectrum drug that is protective against Zygomycota and Fusarium, Penicillium, Histoplasma, Blastomyces, Coccidioides, Paracoccidioides, Sporotrix, chromoblastomycosis, mycetoma, phaeohyphomycosis, including Scedosporium apiospermum and Exophiala, Alternaria, and Bipolaris spp. [89]. Among other things it has been used for the successful treatment of Cunninghamella elegans infection [90]. Furthermore, it is the most active drug in A. elegans treatment, has lower MIC than AmpB [91]. Saksenaeaceae (Apophysomyces and Saksenaea) seem to be most responsive to the antifungals posaconazole, itraconazole, and terbinafine [92], but not AmpB.

\section{Voriconazole}

Previous exposure of Rhizopus oryzae to voriconazole enhances virulence in animal models [93, 94]. It is discussed whether the co-occurrence of voriconazole application for antifungal prophylaxis in immunocompromised patients with the frequency of zygomycosis is of a causal nature [4]

\section{Caspofungin}

Reports of caspofungin treatment show discrepancies between in vitro and in vivo results. It is claimed that caspofungin facilitates the development of some zygomycoses in a similar manner to voriconazole and is associated with a worse outcome [65]. On the other hand, caspofungin shows synergy with AmpB in a mouse model [95]. There is a repeatedly confirmed paradox of caspofungin efficacy decreasing to control level when administered in higher doses in murine models [96].

\section{Terbinafine}

Recently, terbinafine has been successfully administered in patients with mucormycosis [83, 97, 98]. The drug has been primarily used against dermatophytes, but further usage included Candida and Zygomycota. Terbinafine was the most active compound (among amphotericin B, voriconazole, posaconazole, itraconazole, ravuconazole, terbinafine, and caspofungin) in an in vitro study of antifungal activity against five strains of Cunninghamella bertholletiae and four of Cunninghamella echinulata [99]. However, it is intriguing why in vivo studies did not include this compound. Nevertheless, the compound was successfully applied against Basidiobolus ranarum in a combination with itraconazole in a rhino-facial infection [100].

\section{Combined antifungal therapy}

Spellberg with colleagues [101] formulated three recommendations to introduce phase III clinical trials with combined therapy:

1. Improved survival in relevant animal models of mucormycosis

2. Available retrospective data that are concordant with the preclinical models both for efficacy and safety

3. Involvement of already approved therapeutic agents

The consortium proposed three potentially effective therapeutic combinations: lipid polyene and echinocandin, lipid polyene/posaconazole and deferasirox, and lipid polyene and posaconazole/isavuconazole. The aforementioned (L)AmpB and posaconazole combination was the most commonly used combined therapy in patients with hematological diseases reported from the SEIFEM and FUNGISCOPE registries. In the aforementioned studies $\mathrm{LAmB}+\mathrm{POS}$ was administered when antifungal monotherapy failed to produce a response. These patients were treated with a monotherapy for a median time of 18 days before LAmB+POS combined therapy was introduced. A robust and consistent assessment of drug efficacy and the influence of combined therapy on patients' outcome is limited by such factors as the limited number of cases, the lack of regular therapeutic drug monitoring, the uncontrolled impact of surgical debridement, and the burden of underlying diseases.

The concluding remark from the analyses of Pagano and colleagues [88] was that a combined antifungal treatment with LAmB+POS may be considered in patients with very aggressive forms of IM. This is the only drug combination that is consistently recommended by independent authorities. However, other combinations have been described as well.

In vitro studies as well as animal studies suggested a synergistic effect of deferasirox in combination with $\mathrm{LAmB}$ [102]. However, a randomized, double-blinded, placebocontrolled trial showed that patients with mucormycosis treated with deferasirox with LAmB had a higher mortality rate at 90 days than patients treated with $\mathrm{LAmB}$ with placebo. Authors emphasized that population imbalances in this small phase II study limit possible generalizations. Spellberg and co-authors concluded that although no obvious toxicities were identified, deferasirox cannot be recommended as part of an initial combination regimen for the treatment of mucormycosis [103].

From the theoretical point of view echinocandins should be active against Mucorales: $R$. oryzae produces the target enzyme for echinocandins [103]. In vitro studies show higher MICs for this group of drugs [104]. In a mouse model of disseminated mucormycosis a combination of caspofungin with ABLC [95] and LAmB with either micafungin or 
anidulafungin [105] markedly and synergistically improved survival compared with either monotherapy or placebo. Reed and colleagues conducted a retrospective study concluding that either ABLC or LAmB combined with CASP improved survival for patients with rhinocerebral mucormycosis compared with polyene monotherapy [106]. Micafungin was also successfully combined with LAmpB; however, systematic trials are lacking [107]. This effect was previously observed in an animal model of disseminated mucormycosis [105]. All these data "provide strong a rationale for a phase III, randomized double-blinded, placebo-controlled study to determine whether lipid polyene plus echinocandins are indeed superior to lipid polyene plus placebo therapy" [103].

\section{Alternative therapy \\ Iron chelators and hyperbaric oxygen}

Both iron chelators (deferasirox and deferiprone) and hyperbaric oxygen have been used in some cases. However, they are not well documented enough to get positive recommendations from ECIL 3 [45].

\section{Immunotherapy and immunostimulation}

Adoptive immunotherapy with $\mathrm{T}$ cells after stimulation with cellular extracts of fungi may form the basis for future clinical trials. Simultaneous stimulation with Aspergillus fumigatus, Candida albicans, and Rhizopus oryzae extracts enables a generation of multi-specific $\mathrm{T}$ cells that recognize a wide variety of taxa [108]. These in vitro and in vivo results may represent a hope for allogeneic hematopoietic stem cell transplantation recipients with invasive fungal infection. However, there is no sufficient clinical evidence to formulate recommendations to use this approach in systemic zygomycosis [109].

The ECIL 3 suggests that the growth factors granulocyte colony-stimulating factor (G-CSF), granulocyte macrophage colony-stimulating factor (GM-CSF), and interferon- $\gamma$ (IFN- $\gamma$ ) should be used in neutropenic patients with mucormycosis. Their administration in other patients needs to be studied further.

\section{Final remarks}

The constantly growing number of patients susceptible to fungal infections emphasizes the critical need for better treatment and diagnostics. These can be developed based on rigorous meta-analyses of well-described case reports with proper taxon identification, treatment, and outcome description.
Acknowledgements This research was supported by National Science Centre grant 2012/07/D/NZ2/04286 to A.M.

Conflict of interest The authors declare that they have no conflict of interest.

Open Access This article is distributed under the terms of the Creative Commons Attribution License which permits any use, distribution, and reproduction in any medium, provided the original author(s) and the source are credited.

\section{References}

1. Krings M, Taylor TN, Dotzler N (2013) Fossil evidence of the zygomycetous fungi. Persoonia 30(1):1-10. doi:10.3767/ 003158513 X664819

2. Almyroudis NG, Nikolaos G, Nikolaos G, Sutton DA, Fothergill AW, Rinaldi MG, Kusne S (2007) In vitro susceptibilities of 217 clinical isolates of zygomycetes to conventional and new antifungal agents. Antimicrob Agents Chemother 51(7):2587-2590. doi:10. 1128/AAC.00452-07

3. Farina C, Marchesi G, Passera M, Diliberto C, Russello G (2012) Comparative study of the in vitro activity of various antifungal drugs against Scedosporium spp. in aerobic and hyperbaric atmosphere versus normal atmosphere. J Mycol Med 22(2):142-148. doi:10.1016/j.mycmed.2012.01.001

4. Pongas GN, Lewis RE, Samonis G, Kontoyiannis DP (2009) Voriconazole-associated zygomycosis: a significant consequence of evolving antifungal prophylaxis and immunosuppression practices? Clin Microbiol Infect 15 [Suppl 5]:93-97. doi:10.1111/j. 1469-0691.2009.02988.x

5. Kontoyiannis DP, Marr KA, Park BJ, Alexander BD, Anaissie EJ, Walsh TJ, Pappas PG (2010) Prospective surveillance for invasive fungal infections in hematopoietic stem cell transplant recipients, 2001-2006: overview of the Transplant-Associated Infection Surveillance Network (TRANSNET) Database. Clin Infect Dis 50(8):1091-1100. doi:10.1086/651263

6. Lewis RE, Lortholary O, Spellberg B, Roilides E, Kontoyiannis DP, Walsh TJ (2012) How does antifungal pharmacology differ for mucormycosis versus aspergillosis? Clin Infect Dis 54 [Suppl 1]: S67-S72. doi:10.1093/cid/cir884

7. Pagano L, Caira M, Candoni A, Offidani M, Fianchi L, Martino B, Nosari A (2006) The epidemiology of fungal infections in patients with hematologic malignancies: the SEIFEM-2004 study. Haematologica 91(8):1068-1075. Retrieved from http://www. ncbi.nlm.nih.gov/pubmed/16885047

8. Roden MM, Zaoutis TE, Buchanan WL, Knudsen TA, Sarkisova TA, Schaufele RL, Walsh TJ (2005) Epidemiology and outcome of zygomycosis: a review of 929 reported cases. Clin Infect Dis 41(5): 634-653. doi:10.1086/432579

9. Vikram HR, Smilack JD, Leighton JA, Crowell MD, De Petris G (2012) Emergence of gastrointestinal basidiobolomycosis in the United States, with a review of worldwide cases. Clin Infect Dis 54(12):1685-1691. Retrieved from http://www.ncbi.nlm.nih.gov/ pubmed/22441651

10. Baradkar VP, Mathur M, Taklikar S, Rathi M, Kumar S (2008) Fatal rhino-orbito-cerebral infection caused by Saksenaea vasiformis in an immunocompetent individual: first case report from India. Indian J Med Microbiol 26(4):385-387. Retrieved from http://www.ncbi. nlm.nih.gov/pubmed/18974499

11. Thomas AJ, Shah S, Mathews MS, Chacko N (2008) Apophysomyces elegans - renal mucormycosis in a healthy host: 
a case report from south India. Indian J Med Microbiol 26(3):269271, Retrieved from http://www.ncbi.nlm.nih.gov/pubmed/ 18695332

12. Hoffmann K, Pawłowska J, Walther G, Wrzosek M, de Hoog GS, Benny GL, Voigt K (2013) The family structure of the Mucorales: a synoptic revision based on comprehensive multigene-genealogies. Persoonia 30(1):57-76. doi:10.3767/003158513X666259

13. Gryganskyi AP, Humber RA, Smith ME, Hodge K, Huang B, Voigt K, Vilgalys R (2013) Phylogenetic lineages in Entomophthoromycota. Persoonia 30(1):94-105. doi:10.3767/ 003158513 X666330

14. Wagner L, Stielow B, Hoffmann K, Petkovits T, Papp T, Vágvölgyi C, Voigt K (2013) A comprehensive molecular phylogeny of the Mortierellales (Mortierellomycotina) based on nuclear ribosomal DNA. Persoonia 30(1):77-93. doi:10.3767/003158513X666268

15. Ainsworth GC (2008) Ainsworth \& Bisby's dictionary of the fungi. Retrieved from http://www.google.pl/books?hl=pl\&lr=\&id=IFD4 VFRDdUC\&pgis $=1$

16. Lu X-L, Najafzadeh MJ, Dolatabadi S, Ran Y-P, Gerrits van den Ende AHG, Shen Y-N, de Hoog GS (2013) Taxonomy and epidemiology of Mucor irregularis, agent of chronic cutaneous mucormycosis. Persoonia 30(1):48-56. doi:10.3767/003158513X665539

17. Segvić Klarić M, Pepeljnjak S (2006) A year-round aeromycological study in Zagreb area, Croatia. Ann Agric Environ Med 13(1):55-64. Retrieved from http://www.ncbi.nlm. nih.gov/pubmed/16841873

18. Vesper SJ, Wymer LJ, Meklin T, Varma M, Stott R, Richardson M, Haugland RA (2005) Comparison of populations of mould species in homes in the UK and USA using mould-specific quantitative PCR. Lett Appl Microbiol 41(4):367-373. doi:10.1111/j.1472765X.2005.01764.x

19. Ejdys E (2007) Fungi isolated in school buildings. Acta Mycol 42(2):245-254

20. Gniadek A, Macura AB (2007) Intensive care unit environment contamination with fungi. Adv Med Sci 52:283-287. Retrieved from http://www.ncbi.nlm.nih.gov/pubmed/18217434

21. El-Herte RI (2012) Mucormycosis: a review on environmental fungal spores and seasonal variation of human disease. Adv Infect Dis 2(3):76-81. doi:10.4236/aid.2012.23012

22. Khan ZU, Ahmad S, Brazda A, Chandy R (2009) Mucor circinelloides as a cause of invasive maxillofacial zygomycosis: an emerging dimorphic pathogen with reduced susceptibility to posaconazole. J Clin Microbiol 47(4):1244-1248. doi:10.1128/ JCM.02030-08

23. Desjardins CA, Champion MD, Holder JW, Muszewska A, Goldberg J, Bailão AM, Cuomo CA (2011) Comparative genomic analysis of human fungal pathogens causing paracoccidioidomycosis. PLoS Genet 7(10), e1002345. doi:10. 1371/journal.pgen.1002345

24. Lee SC, Li A, Calo S, Heitman J (2013) Calcineurin plays key roles in the dimorphic transition and virulence of the human pathogenic zygomycete mucor circinelloides. PLoS Pathog 9(9):e1003625. doi: 10.1371/journal.ppat.1003625

25. Singh R, Shivaprakash MR, Chakrabarti A (2011) Biofilm formation by zygomycetes: quantification, structure and matrix composition. Microbiology 157(Pt 9):2611-2618. doi:10.1099/mic.0.048504-0

26. Ma L-J, Ibrahim AS, Skory C, Grabherr MG, Burger G, Butler M, Wickes BL (2009) Genomic analysis of the basal lineage fungus Rhizopus oryzae reveals a whole-genome duplication. PLoS Genet 5(7):e1000549. doi:10.1371/journal.pgen.1000549

27. Hibbett DS, Taylor JW (2013) Fungal systematics: is a new age of enlightenment at hand? Nat Rev Microbiol 11(2):129-133. doi:10. 1038/nrmicro2963

28. Voigt K, Vaas L, Stielow B, de Hoog GS (2013) The zygomycetes in a phylogenetic perspective. Persoonia 30(1):1-4. doi:10.3767/ 003158513 X666277
29. Alvarez E, Garcia-Hermoso D, Sutton DA, Cano JF, Stchigel AM, Hoinard D, Guarro J (2010) Molecular phylogeny and proposal of two new species of the emerging pathogenic fungus Saksenaea. J Clin Microbiol 48(12):4410-4416. doi:10.1128/JCM.01646-10

30. Alvarez E, Stchigel AM, Cano J, Sutton DA, Fothergill AW, Chander J, Guarro J (2010) Molecular phylogenetic diversity of the emerging mucoralean fungus Apophysomyces: Proposal of three new species. Rev Iberoam Micol 27(2):80-89. doi:10.1016/ j.riam.2010.01.006

31. Alvarez E, Cano J, Stchigel AM, Sutton DA, Fothergill AW, Salas V, Guarro J (2011) Two new species of Mucor from clinical samples. Med Mycol 49(1):62-72. doi:10.3109/13693786.2010. 499521

32. Dolatabadi S, Walther G, Gerrits van den Ende AHG, Hoog GS (2013) Diversity and delimitation of Rhizopus microsporus. Fungal Divers. doi:10.1007/s13225-013-0229-6

33. Gauthier GM, Keller NP (2013) Crossover fungal pathogens: the biology and pathogenesis of fungi capable of crossing kingdoms to infect plants and humans. Fungal Genet Biol. doi:10.1016/j.fgb.2013. 08.016

34. Roilides E, Kontoyiannis DP, Walsh TJ (2012) Host defenses against zygomycetes. Clin Infect Dis 54 [Suppl 1]:S61-S66. doi: 10.1093/cid/cir869

35. Ibrahim AS, Kontoyiannis DP (2013) Update on mucormycosis pathogenesis. Curr Opin Infect Dis. doi:10.1097/QCO. 0000000000000008

36. Ibrahim AS, Spellberg B, Walsh TJ, Kontoyiannis DP (2012) Pathogenesis of mucormycosis. Clin Infect Dis Off Publ Infect Dis Soc Am 54 [Suppl 1]:S16-S22. doi:10.1093/cid/cir865

37. Liu M, Spellberg B, Phan QT, Fu Y, Fu Y, Lee AS, Ibrahim AS (2010) The endothelial cell receptor GRP78 is required for mucormycosis pathogenesis in diabetic mice. J Clin Invest 120(6): 1914-1924. doi:10.1172/JCI42164

38. Schmidt S, Tramsen L, Perkhofer S, Lass-Flörl C, Hanisch M, Röger F, Lehrnbecher T (2013) Rhizopus oryzae hyphae are damaged by human natural killer (NK) cells, but suppress NK cell mediated immunity. Immunobiology 218(7):939-944. doi:10. 1016/j.imbio.2012.10.013

39. Gil-Lamaignere C, Simitsopoulou M, Roilides E, Maloukou A, Winn RM, Walsh TJ (2005) Interferon- gamma and granulocytemacrophage colony-stimulating factor augment the activity of polymorphonuclear leukocytes against medically important zygomycetes. J Infect Dis 191(7):1180-1187. doi:10.1086/428503

40. Gupta R, Goel N, Gupta A, Gupta KB, Chaudhary U, Sood S (2011) A rare fungal infiltration of lungs in a healthy young girl. Case Rep Pulmonol 2011:917089. doi:10.1155/2011/917089

41. Rammaert B, Lanternier F, Poirée S, Kania R, Lortholary O (2012) Diabetes and mucormycosis: a complex interplay. Diabetes Metab 38(3):193-204. doi:10.1016/j.diabet.2012.01.002

42. Prabhu RM, Patel R (2004) Mucormycosis and entomophthoramycosis: a review of the clinical manifestations, diagnosis and treatment. Clin Microbiol Infect 10 [Suppl 1]:31-47. Retrieved from http://www.ncbi.nlm.nih.gov/pubmed/14748801

43. Zaki SM, Elkholy IM, Elkady NA, Abdel-Ghany K (2013) Mucormycosis in Cairo, Egypt: review of 10 reported cases. Med Mycol. doi:10.3109/13693786.2013.809629

44. Chayakulkeeree M, Ghannoum MA, Perfect JR (2006) Zygomycosis: the re-emerging fungal infection. Eur J Clin Microbiol Infect Dis 25(4):215-229. doi:10.1007/s10096-0060107-1

45. Skiada A, Lanternier F, Groll AHA, Pagano L, Zimmerli S, Herbrecht R, Petrikkos GL (2013) Diagnosis and treatment of mucormycosis in patients with hematological malignancies: guidelines from the 3rd European Conference on Infections in Leukemia (ECIL 3). Haematologica 98(4):492-504. doi:10.3324/haematol. 2012.065110 
46. Sun H-YH, Singh N (2011) Mucormycosis: its contemporary face and management strategies. Lancet Infect Dis 11(4):301-311. doi: 10.1016/S1473-3099(10)70316-9

47. Mysorekar VV, Rao SG (2008) Cytomegalovirus pneumonia with pulmonary mucormycosis. Indian J Pathol Microbiol 51(2):294-295. Retrieved from http://www.ncbi.nlm.nih.gov/pubmed/18603715

48. Andresen D, Donaldson A, Choo L, Knox A, Klaassen M, Ursic C, Konecny P (2005) Multifocal cutaneous mucormycosis complicating polymicrobial wound infections in a tsunami survivor from Sri Lanka. Lancet 365(9462):876-878. doi:10.1016/S0140-6736(05)71046-1

49. Ledgard JP, van Hal S, Greenwood JE (2008) Primary cutaneous zygomycosis in a burns patient: a review. J Burn Care Res 29(2): 286-290. doi:10.1097/BCR.0b013e31816673b1

50. Peleg AY, Weerarathna T, McCarthy JS, Davis TME (2007) Common infections in diabetes: pathogenesis, management and relationship to glycaemic control. Diabetes/Metab Res Rev 23(1): 3-13. doi:10.1002/dmrr.682

51. Rammaert B, Lanternier F, Zahar J-R, Dannaoui E, Bougnoux M-E, Lecuit M, Lortholary O (2012) Healthcare-associated mucormycosis. Clin Infect Dis 54 [Suppl 1]:S44-S54. doi:10. 1093/cid/cir867

52. Petrikkos G, Skiada A, Lortholary O, Roilides E, Walsh TJ, Kontoyiannis DP (2012) Epidemiology and clinical manifestations of mucormycosis. Clin Infect Dis 54 [Suppl 1]:S23-S34. doi:10. 1093/cid/cir866

53. Spellberg B, Edwards J, Ibrahim A (2005) Novel perspectives on mucormycosis: pathophysiology, presentation, and management. Clin Microbiol Rev 18(3):556-569. doi:10.1128/CMR.18.3.556569.2005

54. Bakr A, Wafa E, Fouda A, Elagroudy A, Gheith O, Sobh M, Ghoneim M (2008) Successful treatment of mucormycosis in a renal allograft recipient. Clin Exp Nephrol 12(3):207-210. doi:10. 1007/s10157-008-0028-7

55. Austin CL, Finley PJ, Mikkelson DR, Tibbs B (2013) Mucormycosis: a rare fungal infection in tornado victims. J Burn Care Res. doi:10.1097/BCR.0b013e318299d4bb

56. Ribeiro NFF, Heath CH, Kierath J, Rea S, Duncan-Smith M, Wood FM (2010) Burn wounds infected by contaminated water: case reports, review of the literature and recommendations for treatment. Burns 36(1):9-22. doi:10.1016/j.burns.2009.03.002

57. Rees JR, Pinner RW, Hajjeh RA, Brandt ME, Reingold AL (1998) The epidemiological features of invasive mycotic infections in the San Francisco Bay area, 1992-1993: results of population-based laboratory active surveillance. Clin Infect Dis 27(5):1138-1147. Retrieved from http://www.ncbi.nlm.nih.gov/pubmed/9827260

58. Torres-Narbona M, Guinea J, Martínez-Alarcón J, Muñoz P, Gadea I, Bouza E (2007) Impact of zygomycosis on microbiology workload: a survey study in Spain. J Clin Microbiol 45(6):2051-2053. doi:10.1128/JCM.02473-06

59. Brown GD, Denning DW, Gow NAR, Levitz SM, Netea MG, White TC (2012) Hidden killers: human fungal infections. Sci Transl Med 4(165):165rv13. doi:10.1126/scitranslmed.3004404

60. Hotchi M, Okada M, Nasu T (1980) Present state of fungal infections in autopsy cases in Japan. Am J Clin Pathol 74(4):410-416. Retrieved from http://www.ncbi.nlm.nih.gov/pubmed/7424823

61. Tietz HJ, Brehmer D, Jänisch W, Martin H (1998) [Incidence of endomycoses in the autopsy material of the Berlin Charite Hospital]. Mycoses 41 [Suppl 2]:81-85. Retrieved from http:// www.ncbi.nlm.nih.gov/pubmed/10085694

62. Yanagisawa E, Friedman S, Kundargi RS, Smith HW (1977) Rhinocerebral phycomycosis. Laryngoscope 87(8):1319-1335. doi:10.1288/00005537-197708000-00012

63. Lanternier F, Dannaoui E, Morizot G, Elie C, Garcia-Hermoso D, Huerre M, Lortholary O (2012) A global analysis of mucormycosis in France: the RetroZygo Study (2005-2007). Clin Infect Dis 54 [Suppl 1]:S35-S43. doi:10.1093/cid/cir880
64. Rüping MJGT, Heinz WJ, Kindo AJ, Rickerts V, Lass-Flörl C, Beisel C, Cornely OA (2010) Forty-one recent cases of invasive zygomycosis from a global clinical registry. J Antimicrob Chemother 65(2):296-302. doi:10.1093/jac/dkp430

65. Skiada A, Pagano L, Groll A, Zimmerli S, Dupont B, Lagrou K, Petrikkos G (2011) Zygomycosis in Europe: analysis of 230 cases accrued by the registry of the European Confederation of Medical Mycology (ECMM) Working Group on Zygomycosis between 2005 and 2007. Clin Microbiol Infect 17(12):1859-1867. doi:10. 1111/j.1469-0691.2010.03456.x

66. Cook MB, Dawsey SM, Freedman ND, Inskip PD, Wichner SM, Quraishi SM, McGlynn KA (2009) Sex disparities in cancer incidence by period and age. Cancer Epidemiol Biomarkers Prev 18(4): 1174-1182. doi:10.1158/1055-9965.EPI-08-1118

67. Sant M, Allemani C, Tereanu C, De Angelis R, Capocaccia R, Visser O, Berrino F (2010) Incidence of hematologic malignancies in Europe by morphologic subtype: results of the HAEMACARE project. Blood 116(19):3724-3734. doi:10.1182/blood-2010-05282632

68. Omoti C, Nwannadi A, Obieche J, Olu-Eddo A (2012) The Epidemiological features of lymphoid malignancies in Benin City, Nigeria: a 15 years study. Pan Afr Med J. doi:10.4314/pamj.v11i1

69. Skiada A Rigopoulos D, Larios G (2012) Global epidemiology of cutaneous zygomycosis. Clin Dermatol 30(6):628-632. Retrieved from http://www.sciencedirect.com/science/article/pii/ S0738081X12000405

70. Montagna MT, De Giglio O, Napoli C, Lovero G, Caggiano G, Delia M, Specchia G (2012) Invasive fungal infections in patients with hematologic malignancies (aurora project): lights and shadows during 18-months surveillance. Int J Mol Sci 13(1):774-787. doi: 10.3390/ijms 13010774

71. Neofytos D, Horn D, Anaissie E, Steinbach W, Olyaei A, Fishman J, Marr K (2009) Epidemiology and outcome of invasive fungal infection in adult hematopoietic stem cell transplant recipients: analysis of Multicenter Prospective Antifungal Therapy (PATH) Alliance registry. Clin Infect Dis 48(3):265-273. doi:10.1086/ 595846

72. Alsharif M, Cameron SEH, Young J-AH, Savik K, Henriksen JC, Gulbahce HE, Pambuccian SE (2009) Time trends in fungal infections as a cause of death in hematopoietic stem cell transplant recipients: an autopsy study. Am J Clin Pathol 132(5):746-755. doi:10.1309/AJCPV9DC4HGPANKR

73. Danaei G, Finucane MM, Lu Y, Singh GM, Cowan MJ, Paciorek CJ, Ezzati M (2011) National, regional, and global trends in fasting plasma glucose and diabetes prevalence since 1980: systematic analysis of health examination surveys and epidemiological studies with 370 country-years and 2.7 million participants. Lancet 378(9785):31-40. doi:10.1016/S0140-6736(11)60679-X

74. Chakrabarti A, Das A, Mandal J, Shivaprakash MR, George VK, Tarai B, Sakhuja V (2006) The rising trend of invasive zygomycosis in patients with uncontrolled diabetes mellitus. Med Mycol 44(4): 335-342. doi:10.1080/13693780500464930

75. Almyroudis NG, Sutton DA, Linden P, Rinaldi MG, Fung J, Kusne S (2006) Zygomycosis in solid organ transplant recipients in a tertiary transplant center and review of the literature. Am J Transplant 6(10):2365-2374. doi:10.1111/j.1600-6143.2006. 01496.x

76. Mignogna M, Fortuna G, Leuci S (2011) Mucormycosis in immunocompetent patients: a case-series of patients with maxillary sinus involvement and a critical review of the literature. J Infect 15(8): e533-e540. Retrieved from http://www.sciencedirect.com/science/ article/pii/S1201971211000488

77. Scheckenbach K, Cornely O, Hoffmann TK, Engers R, Bier H, Chaker A, Wagenmann M (2010) Emerging therapeutic options in fulminant invasive rhinocerebral mucormycosis. Auris Nasus Larynx 37(3):322-328. doi:10.1016/j.anl.2009.09.001 
78. Prasad PA, Vaughan AM, Zaoutis TE (2012) Trends in zygomycosis in children. Mycoses 55(4):352-356. doi:10.1111/j. 1439-0507.2011.02124.x

79. Roilides E, Zaoutis TE, Katragkou A, Benjamin DK, Walsh TJ (2009) Zygomycosis in neonates: an uncommon but lifethreatening infection. Am J Perinatol 26(8):565-573. doi:10.1055/ s-0029-1220775

80. Chamilos G, Marom EM, Lewis RE, Lionakis MS, Kontoyiannis DP (2005) Predictors of pulmonary zygomycosis versus invasive pulmonary aspergillosis in patients with cancer. Clin Infect Dis 41(1):60-66. doi:10.1086/430710

81. Walsh TJ, Gamaletsou MN, McGinnis MR, Hayden RT, Kontoyiannis DP (2012) Early clinical and laboratory diagnosis of invasive pulmonary, extrapulmonary, and disseminated mucormycosis (zygomycosis). Clin Infect Dis 54 [Suppl 1]:S55S60. doi:10.1093/cid/cir868

82. Lass-Flörl C, Resch G, Nachbaur D, Mayr A, Gastl G, Auberger J, Freund MC (2007) The value of computed tomography-guided percutaneous lung biopsy for diagnosis of invasive fungal infection in immunocompromised patients. Clin Infect Dis 45(7):e101-e104. doi: $10.1086 / 521245$

83. Keller KA (2012) Therapeutic review: terbinafine. J Exot Pet Med 21(2):181-185. doi:10.1053/j.jepm.2012.02.007

84. Schwarz P, Lortholary O, Dromer F, Dannaoui E (2007) Carbon assimilation profiles as a tool for identification of zygomycetes. $\mathrm{J}$ Clin Microbiol 45(5):1433-1439. doi:10.1128/JCM.02219-06

85. Zhao Z, Li L, Wan Z, Chen W, Liu H, Li R (2011) Simultaneous detection and identification of Aspergillus and mucorales species in tissues collected from patients with fungal rhinosinusitis. J Clin Microbiol 49(4):1501-1507. doi: 10.1128/JCM.02262-10

86. Antoniadou A, Dupont B (2005) Lipid formulations of amphotericin B: where are we today? J Mycol Med 15(4):230 238. doi:10.1016/j.mycmed.2005.06.005

87. Klepser M (2011) The value of amphotericin B in the treatment of invasive fungal infections. J Crit Care 26(2):225.e1-225.e10. doi: 10.1016/j.jcrc.2010.08.005

88. Pagano L, Cornely O, Busca A, Caira M, Cesaro S, Gasbarrino C, Vehreschild MJGT (2013) Combined antifungal approach for the treatment of invasive mucormycosis in patients with hematological diseases: a report from the SEIFEM and FUNGISCOPE registries. Haematologica. doi:10.3324/haematol.2012.083063

89. Scheinfeld N (2007) A review of the new antifungals: posaconazole, micafungin, and anidulafungin. J Drugs Dermatol 6(12):1249-1251. Retrieved from http://www.ncbi.nlm.nih.gov/pubmed/18189069

90. Garbino J, Myers C, Ambrosioni J, Gumy-Pause F (2010) Report of a successful treatment of pulmonary Cunninghamella bertholletiae infection with liposomal amphotericin and posaconazole in a child with GvHD and review of the literature. J Pediatr Hematol Oncol 32(2):85-87. doi:10.1097/MPH.0b013e3181c2bdce

91. Chakrabarti A, Shivaprakash MR, Curfs-Breuker I, Baghela A, Klaassen CH, Meis JF (2010) Apophysomyces elegans: epidemiology, amplified fragment length polymorphism typing, and in vitro antifungal susceptibility pattern. J Clin Microbiol 48(12):4580 4585. doi:10.1128/JCM.01420-10

92. Hospenthal DR, Chung KK, Lairet K, Thompson EH, Guarro J, Renz EM, Sutton DA (2011) Saksenaea erythrospora infection following combat trauma. J Clin Microbiol 49(10):3707-3709. doi:10.1128/JCM.05095-11

93. Lamaris GA, Ben-Ami R, Lewis RE, Chamilos G, Samonis G, Kontoyiannis DP (2009) Increased virulence of Zygomycetes organisms following exposure to voriconazole: a study involving fly and murine models of zygomycosis. J Infect Dis 199(9):1399-1406. doi: $10.1086 / 597615$

94. Lewis RE, Liao G, Wang W, Prince RA, Kontoyiannis DP (2011) Voriconazole pre-exposure selects for breakthrough mucormycosis in a mixed model of Aspergillus fumigatus-Rhizopus oryzae pulmonary infection. Virulence 2(4):348-355. Retrieved from http://www.ncbi.nlm.nih.gov/pubmed/21788730

95. Spellberg B, Fu Y, Edwards JE, Ibrahim AS (2005) Combination therapy with amphotericin B lipid complex and caspofungin acetate of disseminated zygomycosis in diabetic ketoacidotic mice. Antimicrob Agents Chemother 49(2):830-832. doi:10.1128/AAC. 49.2.830-832.2005

96. Lewis RE, Leventakos K, Liao G, Kontoyiannis DP (2011) Efficacy of caspofungin in neutropenic and corticosteroidimmunosuppressed murine models of invasive pulmonary mucormycosis. Antimicrob Agents Chemother 55(7):35843587. doi:10.1128/AAC.01812-10

97. Pérez A (1999) Terbinafine: broad new spectrum of indications in several subcutaneous and systemic and parasitic diseases. Mycoses 42(Suppl 2):111-114, Retrieved from http://www.ncbi.nlm.nih.gov/ pubmed/10865916

98. Revankar SG, Nailor MD, Sobel JD (2008) Use of terbinafine in rare and refractory mycoses. Future Microbiol 3(1):9-17. doi:10. 2217/17460913.3.1.9

99. Pastor FJ, Ruíz-Cendoya M, Pujol I, Mayayo E, Sutton DA, Guarro $J$ (2010) In vitro and in vivo antifungal susceptibilities of the Mucoralean fungus Cunninghamella. Antimicrob Agents Chemother 54(11):4550-4555. doi:10.1128/AAC.00786-10

100. Goyal A, Gupta N, Das S, Jain S (2010) Basidiobolomycosis of the nose and face: a case report and a mini-review of unusual cases of basidiobolomycosis. Mycopathologia 170(3):165-168. doi:10. 1007/s11046-010-9310-9

101. Spellberg B, Ibrahim AS, Chin-Hong PV, Kontoyiannis DP, Morris MI, Perfect JR, Brass EP (2012) The Deferasirox-AmBisome Therapy for Mucormycosis (DEFEAT Mucor) study: a randomized, double-blinded, placebo-controlled trial. J Antimicrob Chemother 67(3):715-722. doi:10.1093/jac/dkr375

102. Ibrahim AS, Bowman JC, Avanessian V, Brown K, Spellberg B, Edwards JE, Douglas CM (2005) Caspofungin inhibits Rhizopus oryzae 1,3-beta-D-glucan synthase, lowers burden in brain measured by quantitative PCR, and improves survival at a low but not a high dose during murine disseminated zygomycosis. Antimicrob Agents Chemother 49(2):721-727. doi:10.1128/AAC.49.2.721-727.2005

103. Spellberg B, Ibrahim A, Roilides E, Lewis RE, Lortholary O, Petrikkos G, Walsh TJ (2012) Combination therapy for mucormycosis: why, what, and how? Clin Infect Dis 54 [Suppl 1]: S73-S78. doi:10.1093/cid/cir885

104. Vitale RG, de Hoog GS, Schwarz P, Dannaoui E, Deng S, Machouart M, Walther G (2012) Antifungal susceptibility and phylogeny of opportunistic members of the order mucorales. J Clin Microbiol 50(1):66-75. doi:10.1128/JCM.06133-11

105. Ibrahim AS, Gebremariam T, Fu Y, Edwards JE, Spellberg B (2008) Combination echinocandin-polyene treatment of murine mucormycosis. Antimicrob Agents Chemother 52(4):1556-1558. doi:10.1128/AAC.01458-07

106. Reed C, Bryant R, Ibrahim AS, Edwards J, Filler SG, Goldberg R, Spellberg B (2008) Combination polyene-caspofungin treatment of rhino-orbital-cerebral mucormycosis. Clin Infect Dis 47(3):364 371. doi:10.1086/589857

107. Ogawa T, Takezawa K, Tojima I, Shibayama M, Kouzaki H, Ishida M, Okabe H, Shimizu T (2012) Successful treatment of rhinoorbital mucormycosis by a new combination therapy with liposomal amphotericin B and micafungin. Auris Nasus Larynx 39(2):224 228. doi: 10.1016/j.anl.2011.03.006

108. Tramsen L, Schmidt S, Boenig H, Latgé J-P, Lass-Flörl C, Roeger F, Lehrnbecher T (2013) Clinical-scale generation of multi-specific antifungal $\mathrm{T}$ cells targeting Candida, Aspergillus and mucormycetes. Cytotherapy 15(3):344-351. doi:10.1016/j.jcyt.2012.11.014

109. Antachopoulos C, Katragkou A, Roilides E (2012) Immunotherapy against invasive mold infections. Immunotherapy 4(1):107-120. doi:10.2217/imt.11.159 